\title{
Analysis of Main Influencing Factors of Global Electrification Development
}

\author{
Junshu Feng ${ }^{1, *}$ and Peng Wang ${ }^{1}$ \\ ${ }^{1}$ State Grid Energy Research Institute Co., Itd, Changping, Beijing, China
}

\begin{abstract}
Based on the analysis of electrification development process in major countries, this paper systematically studied and judged 5 important influencing factors of electrification development in the world, including resource endowment, economic development, improvement of people's livelihood, infrastructure and policy guidance, among economic development includes industrial structure and urbanization level. The opinions of this paper can support different regions or countries to choose proper electrification development paths.
\end{abstract}

\section{Introduction}

In the context of a joint global response to climate change, it is a strategic choice for countries worldwide to realize clean and low-carbon energy development centered on electricity utilization [1-3]. Hence, studying and judging the important influencing factors of electrification development is of great necessity for different regions to choose proper electrification development paths.

Based on the analysis of the development process of electrification in major countries, this paper systematically studies and judges five important factors of electrification development in the world: resource endowment, economic development, improvement of people's livelihood, infrastructure and policy guidance, among economic development includes industrial structure and urbanization level.

\section{Resource endowment}

Resource conditions determine the energy variety for final consumption and their economy, and to a certain extent determine the level of electrification. As some renewable energy sources such as hydropower, wind energy, solar energy and geothermal energy need to be converted into electricity for convenient and intelligent use, the electrification level is directly affected by resource endowment.

For example, as shown in figure 1, Iceland is the country with the richest geothermal resources in the world. It is also rich in water resources, but other energy resources are scarce. Therefore, Iceland's energy system relies mainly on hydropower and geothermal power generation, according to International Energy Agency (IEA), with a total power generation of 19.2 billion $\mathrm{kWh}$ in 2017, of which hydropower accounted for $73 \%$, geothermal power generation $26.9 \%$, and wind power and fossil energy power generation $0.1 \%$.With the commissioning of new geothermal power stations and hydropower stations, Iceland's electrification level is also rising steadily. In 2017, the electrification level has reached $52 \%$.

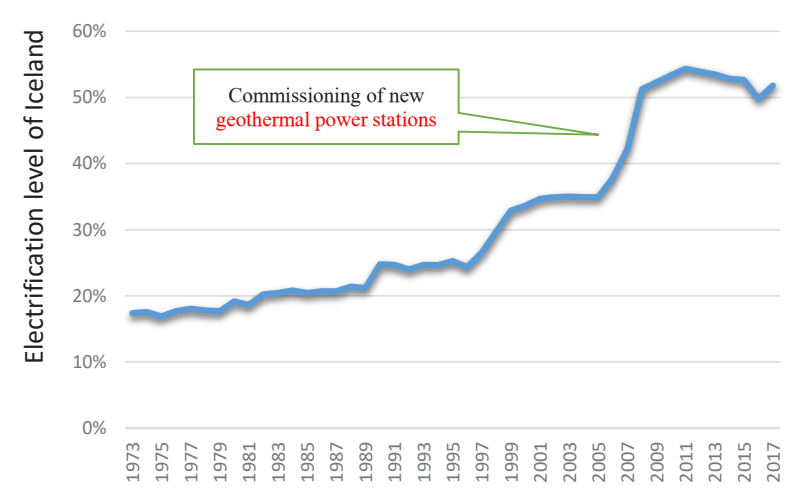

Fig. 1. Change Trend of the Electrification Level in Iceland (Data source: IEA)

\section{Economic development}

Electrification level and economic development promote and influence each other. As shown in figure 2, economic development requires further improvement of labor efficiency and promotes electrification of final energy consumption. The industrial revolution greatly improved labor efficiency, created huge productivity and realized the leap from manual production to mechanical production. Especially since the second industrial revolution, the world has entered an era of production of relays and electrical automation controlled mechanical equipment. The large-scale production of electric-driven products has been achieved, and a new high-efficiency mode of mass production of products has been introduced through the successful separation of parts production and product assembly. Specifically, the

\footnotetext{
* Corresponding author: fengjunshu@sgeri.sgcc.com.cn
} 
adjustment of industrial structure and the process of urbanization in economic development have a great impact on electrification.

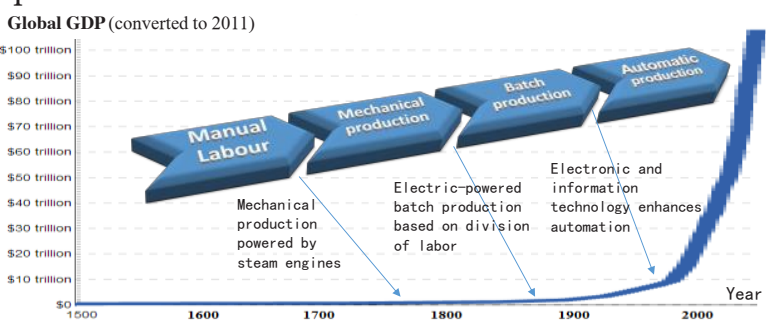

Fig. 2. Changes in Global GDP and Development Trend of Industrial Revolution (Source: New Maddison Project Database, World Bank)

\subsection{Industrial structure}

With the progress and development of the economy, the industrial structure has been continuously adjusted to the secondary and tertiary industries, boosting the improvement of the electrification level. The demand for electricity in different economic sectors is obviously different, and the industrial structure has a great impact on the level of electrification [4]. Take the electrification level of various sectors in the United States as an example as shown in figure 3. The electrification level from low to high is transportation, industry, residents and commerce. Judging from the economic development history of developed countries, the process of economic restructuring is to a large extent manifested in the sequential evolution from the dominant proportion of the primary industry to the dominant proportion of the secondary and tertiary industries, i.e. from low-level electrification sectors to high-level electrification sectors.

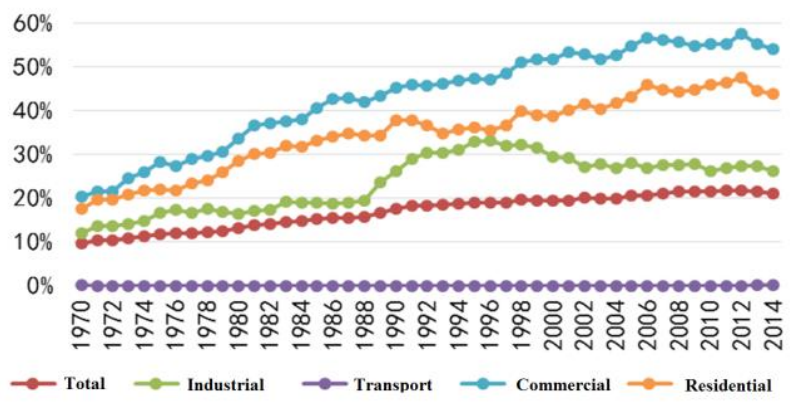

Fig. 3. Changes in Electrification Level of Final Subsectors in the United States (Data source: IEA)

\subsection{Urbanization}

The urbanization process has also continuously promoted the development of electrification. With the continuous improvement of urbanization rate, people are witnessing improvement in their living standard and life quality, and they are more inclined to use convenient and efficient electric energy for energy consumption. The electrification level continues to rise. According to IEA and World Bank, from 1980 to 2017, the global urbanization rate increased by about 15.5 percentage points, while the electrification level increased by 8.0 percentage points, as shown in figure 4 .

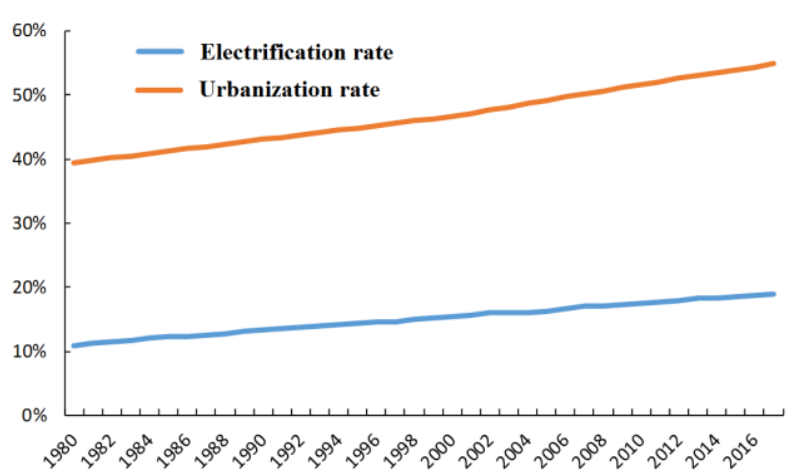

Fig. 4. Change Trend of Urbanization Rate and Electrification Rate Since 1980 (Data source: Word Bank, IEA)

International developed cities can be divided into three levels according to electrification rates, as shown in table 1. In the first level, the energy consumption of the cities is mainly electricity and oil, while the proportion of natural gas consumption is low, and the electrification level is over $40 \%$. For example, the electrification level of Hong Kong is 41.8\%. The consumption ratio of oil and gas in the second level cities is significant, ranging from $50 \%$ to $70 \%$, and the electrification level is between $30 \%$ and $40 \%$. For example, the electrification level in Tokyo, Paris and London is $33.8 \%, 32.8 \%$ and $30.5 \%$ respectively. In the third level cities, the proportion of oil and gas consumption exceeds $70 \%$, and the electrification level is lower than $30 \%$. For example, the electrification level of Singapore, Los Angeles and New York is 23.0\%, $22.4 \%$ and $18.0 \%$ respectively.

Table 1. Final energy consumption structure and electrification rate in developed cities

\begin{tabular}{|c|c|c|c|c|c|}
\hline \multirow{2}{*}{ City } & \multirow{2}{*}{ Year } & \multicolumn{4}{|c|}{$\begin{array}{c}\text { Consumption ratio in total final } \\
\text { energy consumption }\end{array}$} \\
\cline { 3 - 6 } & & Coal & Oil & Gas & $\begin{array}{c}\text { Electri } \\
\text {-city }\end{array}$ \\
\hline Hong Kong & 2014 & $17.3 \%$ & $32.4 \%$ & $6.8 \%$ & $41.8 \%$ \\
\hline Tokyo & 2011 & $11.4 \%$ & $25.3 \%$ & $24.6 \%$ & $33.8 \%$ \\
\hline Pairs & 2011 & $0.2 \%$ & $33.0 \%$ & $32.4 \%$ & $32.8 \%$ \\
\hline London & 2012 & $0.1 \%$ & $22.1 \%$ & $47.1 \%$ & $30.5 \%$ \\
\hline Singapore & 2014 & $1.0 \%$ & $68.7 \%$ & $7.4 \%$ & $23.0 \%$ \\
\hline $\begin{array}{c}\text { Los } \\
\text { Angeles }\end{array}$ & 2011 & $1.0 \%$ & $42.6 \%$ & $32.0 \%$ & $22.4 \%$ \\
\hline Beijing & 2015 & $8.8 \%$ & $43.4 \%$ & $14.3 \%$ & $21.2 \%$ \\
\hline New York & 2015 & $0.7 \%$ & $47.0 \%$ & $32.2 \%$ & $18.0 \%$ \\
\hline Shang-hai & 2015 & $17.7 \%$ & $53.3 \%$ & $7.7 \%$ & $17.5 \%$ \\
\hline Chong-qing & 2015 & $40.9 \%$ & $17.4 \%$ & $16.7 \%$ & $15.3 \%$ \\
\hline Tian-jin & 2015 & $29.7 \%$ & $35.4 \%$ & $8.0 \%$ & $14.9 \%$ \\
\hline
\end{tabular}


Note: Data of Beijing, Shanghai, Tianjin and Chongqing were taken from national bureau's statistics of China. Data of Hong Kong and Singapore were taken from IEA. London's data were taken from UK's Department of Energy and Climate Change (DECC). New York's data were taken from the U.S. Energy Information Administration (EIA). Data for Tokyo, Paris and Los Angeles were taken from a study by Ontario University.

\section{Improvement of people's livelihood}

The continuous improvement of people's livelihood will also promote the continuous improvement of electrification level, mainly including higher requirements for life quality brought about by the improvement of modernization level in developed countries, and the continuous improvement of living standards in developing countries, which will partially lift people out of poverty. People's rising living standards will propose higher demands for intelligent energy consumption. Electricity is flexible, controllable and changeable, and may interact with information technologies such as the Internet in a more convenient and accurate fashion. In addition, electricity can also be organically integrated with advanced sensing, communication, automatic control and other technologies. Featuring self-management and recovery, strong compatibility and so on, it can meet diversified energy consumption needs, and promote transformation of energy consumption from one-way and passive electricity consumption mode to interactive and flexible intelligent electricity consumption mode.

\section{Infrastructure}

Complete power grid or electricity infrastructure is also the main factor to promote electricity consumption and improve the development level of electrification. Judging from the promotion effect of power grid facilities on electrification, the construction of large power grids can give rise to huge interconnection benefits and generally reduce the cost of final electric energy; judging from the promotion effect of electricity facilities on electrification, the emergence of convenient and economical electricity equipment such as electric vehicles and smart homes will also promote the continuous substitution of electricity at finals.

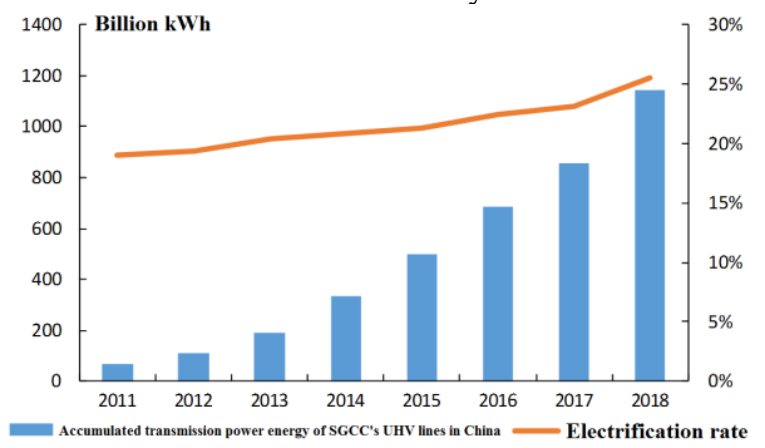

Fig. 5. Change Trend of Corporate UHV Accumulative Transmission Electricity and Electrification Level

\subsection{Power grids}

On the one hand, large power grids are interconnected to promote the level of electrification. Taking the interconnection of large power grids in China as an example. As shown in figure 5, by the end of 2018, the corporate UHV transmission lines have accumulated transmitted about 1.1 trillion $\mathrm{kWh}$ of electricity across regions and provinces. Since the 12th Five-Year Plan, the length of the corporate UHV transmission lines has increased by nearly 10 times and the amount of electricity transmitted has increased by about 16 times. The improvement of trans-regional transmission capacity has effectively promoted the large-scale optimal allocation of power resources and helped improve the electrification level in the country [5].

\subsection{Electricity facilities}

On the other hand, the enrichment and perfection of electricity facilities have expanded the scale of electrification. With the improvement of final power facilities and the enhancement of economy, electricity substitution has gradually been actively promoted in various energy-using industries, including industrial coal to electricity, port electricity, household electrification and other fields. Take China as an example. In 2017, in the field of residential heating, 8.8 billion $\mathrm{kWh}$ of electricity was replaced by heat pumps, decentralized electric heating, electric (storage) boilers and other technologies; in the field of industrial (agricultural) production and manufacturing, 77.4 billion $\mathrm{kWh}$ of electricity was replaced by metallurgical electric furnaces, building materials electric kilns, auxiliary electric power, industrial electric boilers and other technologies; in the field of transportation, 12.8 billion $\mathrm{kWh}$ of electricity was replaced by rail transportation, electric vehicles, port electricity and other technologies.

\section{Policy guidance}

The government's policy guidance is the prerequisite for the wide use of electric energy. Through the formulation of energy substitution policies, fiscal policies, environmental protection policies, etc., the government aims to promote utilization of electric energy.

In terms of energy substitution policies, the two oil crises have prompted countries to actively develop oil substitution energy, which is mostly supplied to users through electricity, thereby making electricity the priority of energy strategies of various countries. Taiwan Province of China also formulated an energy development and economic development strategy focusing on electricity in 1984, proposing to shift from an oil-based economy to an electricity-based economy and to vigorously promote electrification.

In terms of fiscal policy, in the construction of rural electrification in the United States, Australia and other countries, the governments gave financial aid and electricity price subsidies to users, making the improvement of electrification level the embodiment of 
the national will. Also, the Brazilian Development Bank has set up special loans for energy conservation projects. Governments have successively launched national plans to develop electric vehicles to promote the transformation of transportation energy. The United States plans huge investments in energy technology over the next decade to promote the research and development of advanced batteries and electric vehicles.

In terms of environmental protection policies, many EU countries levy taxes on pollutant emissions from energy-intensive industries and levy energy taxes on users for public energy conservation program funds. For example, Denmark imposes a high-level carbon dioxide tax of EUR3.3/ton on the household and industrial sectors, and such tax may be reduced to EUR0.4/ton for users who have signed voluntary agreements on energy conservation. These taxes will bring about a relatively large increase in the cost of energy consumption, thus increasing the cost of energy consumers, restricting their energy consumption behavior and changing their energy consumption pattern.

\section{References}

1. Y.Z. Zhang. An important sign of urban energy transformation - continuous upgrading of electrification level. Energy Review. 2017, 9(V00): 29-31.

2. J.S. Feng, K. Zheng, J.T. Li, G.J. Fu. A Reelectrification Scenario Analysis at a Time of Worldwide Energy Transition. IOP Conference Series: Earth and Environmental Science. 2019, 237: 062028.

3. Y. Du. Further electrification of energy. Technology Overview, 2016, 5(7): 70-71.

4. F. Tian. Economic development, structural transformation, and production capacity cooperation of BRICS. Journal of Latin American Studies, 2017, 39(4): 85-104.

5. K. Zheng, J.F. Zhang, J. Liu, J.S. Feng, G.J. Fu, J.T. Li. Quantitative Analysis of China's Electrification Process Based on the 3E Optimization Model. Electric Power. 2019, 52(4): 17-24. 